\title{
Endovascular Treatment of Diabetic Foot in a Selected Population of Patients with Below-the-Knee Disease: Is the Angiosome Model Effective?
}

\author{
Rita Fossaceca · Giuseppe Guzzardi • Paolo Cerini • \\ Claudio Cusaro - Alessandro Stecco • Giuseppe Parziale • \\ Marco Perchinunno · Marco De Bonis · Alessandro Carriero
}

Received: 8 October 2012/Accepted: 1 December 2012/Published online: 29 January 2013

(C) Springer Science+Business Media New York and the Cardiovascular and Interventional Radiological Society of Europe (CIRSE) 2013

\begin{abstract}
Purpose To evaluate the efficacy of percutaneous transluminal angioplasty (PTA) in a selected population of diabetic patients with below-the-knee (BTK) disease and to analyze the reliability of the angiosome model.

Methods We made a retrospective analysis of the results of PTA performed in 201 diabetic patients with BTK-only disease treated at our institute from January 2005 to December 2011. We evaluated the postoperative technical success, and at 1, 6, and 12 months' follow-up, we assessed the rates and values of partial and complete ulcer healing, restenosis, major and minor amputation, limb salvage, and percutaneous oximetry $\left(\mathrm{TcPO}_{2}\right)$ (Student's $t$ test). We used the angiosome model to compare different clinicolaboratory outcomes in patients treated by direct revascularization (DR) from patients treated with indirect revascularization (IR) technique by Student's $t$ test and the $\chi^{2}$ test.

Results At a mean \pm standard deviation follow-up of $17.5 \pm 12$ months, we observed a mortality rate of $3.5 \%$, a major amputation rate of $9.4 \%$, and a limb salvage rate
\end{abstract}

R. Fossaceca - G. Guzzardi · P. Cerini $(\bowtie)$ - A. Stecco ·

G. Parziale - M. Perchinunno - M. De Bonis - A. Carriero

Department of Diagnostic and Interventional Radiology,

"Maggiore della Carità" Hospital, University of Eastern

Piedmont “Amedeo Avogadro", C.so Mazzini 18, 28100

Novara, NO, Italy

e-mail: cerini84@hotmail.it

R. Fossaceca

e-mail: rfossaceca@hotmail.com

G. Guzzardi

e-mail: guz@libero.it

A. Stecco

e-mail: a.stecco@libero.it of $87 \%$ with a statistically significant increase of $\mathrm{TcPO}_{2}$ values at follow-up compared to baseline $(p<0.05)$. In 34 patients, treatment was performed with the IR technique and in 167 by DR; in both groups, there was a statistically significant increase of $\mathrm{TcPO}_{2}$ values at follow-up compared to baseline $(p<0.05)$, without statistically significant differences in therapeutic efficacy.

Conclusion PTA of the BTK-only disease is a safe and effective option. The DR technique is the first treatment option; we believe, however, that IR is similarly effective, with good results over time.

Keywords Angioplasty/angiogram · Arterial intervention - Arteriosclerosis - Diabetes .

Recanalization $\cdot$ Revascularization

\section{Introduction}

Diabetes mellitus is a disease with great impact in terms of morbidity and mortality, the incidence of which has

\author{
G. Parziale \\ e-mail: giuseppeparziale@gmail.com \\ M. Perchinunno \\ e-mail: marcoperchinunno@gmail.com \\ M. De Bonis \\ e-mail: marco_deb@hotmail.it \\ A. Carriero \\ e-mail: profcarriero@virgilio.it \\ C. Cusaro \\ Department of Diabetic Complications, "Maggiore della Carità" \\ Hospital, C.so Mazzini 18, 28100 Novara, NO, Italy \\ e-mail: claudio.cusaro@libero.it
}


increased rapidly [1]. In 2011, it was estimated that 350 million people worldwide (6.6\% of the population) and 55 million people in Europe were affected by diabetes mellitus [2], with 65 million estimated patients in the European community in 2025 [2]. The most common manifestation in patients with diabetic vasculopathy is diabetic foot. Its main features are foot ulcers, the etiopathogenesis of which recognizes the triad of ischemia, neuropathy, and infection [1]. Diabetic foot complications are the leading cause of hospitalization and major or minor amputation, and these complications represents up to $40 \%$ of health expenditures in diabetic patients [3, 4]. A total of 5-8 \% of patients with diabetic foot will undergo major amputation within 1 year, and $85 \%$ of all amputation are preceded by foot ulcers that subsequently evolve to severe infection and gangrene [5-7].

In recent years, percutaneous transluminal angioplasty (PTA) has become the first-line option in the treatment of diabetic foot, as it allows the healing of ulcers [8]. The primary goal of PTA treatment is to restore the patency of at least one below-the-knee (BTK) vessel, preferably the tributary of the anatomical region of the ulcer [9]. Several studies have demonstrated good results in terms of patency and limb salvage after endovascular treatment of diabetic foot [10-14]. Many, however, are limited by the presence of a heterogeneous population with different stages of ischemia (claudication, rest pain, trophic lesions) and different treatment modalities, with PTA performed both in the above-the-knee (ATK) and BTK areas [15-17]. It is well known that peripheral arterial disease in diabetic patients with critical limb ischemia (CLI) primarily involves the BTK area (anterior and posterior tibial arteries, peroneal artery, dorsalis pedis, medial and lateral plantar arteries) [18], but the efficacy of PTA in this group of BTK-only patients has not been fully evaluated, particularly regarding the different effectiveness of direct revascularization (DR) versus indirect revascularization (IR) according to the angiosome model [19].

The objective of this study was to evaluate the efficacy of PTA in a selected population of patients with BTK-only disease and to compare patients undergoing DR and IR to analyze the reliability of the angiosome model.

\section{Materials and Methods}

We prospectively collected in a Microsoft Excel database the clinical laboratory and imaging (Doppler ultrasound) data of all diabetic patients treated with PTA. We performed a retrospective evaluation of the results obtained in terms of limb salvage and values of percutaneous oximetry $\left(\mathrm{TcPO}_{2}\right)$ in patients with BTK-area ischemic ulcers (Fontaine stage IV, Rutherford stages $\mathrm{V}$ and $\mathrm{VI}$ ) treated from January 2005 to December 2011. To evaluate the effectiveness of PTA in the BTK areas, we excluded from our analysis patients with treatment that extended to the ATK area. Because of its retrospective nature, no approval was necessary from the ethical committee.

We then separated the treatment groups into twopatients undergoing $\mathrm{DR}$ and patients undergoing IR, according to the angiosome model [19]— so we could compare the different outcomes of the clinical laboratory studies, including $\mathrm{TcPO}_{2}$.

The indication for PTA treatment was made on the basis of the detection of reduced or absent pedal and posterior tibial pulse; on values of $\mathrm{TcPO}_{2}$ of $<30 \mathrm{mmHg}$; and on ultrasound Doppler detection of significant stenosis (caliber reduction $>70 \%$, peak systolic velocity [PSV] $>4 \mathrm{~m} / \mathrm{s}$, PSV stenosis/PSV upstream $>4: 1$ ).

PTA was performed in most cases after removal of the necrotic tissue, administration of broad-spectrum antibiotic therapy, and dual antiplatelet therapy (aspirin $100 \mathrm{mg} /$ day, clopidogrel $75 \mathrm{mg} /$ day). PTA procedures were performed in the angiography suite using dedicated digital angiography (Integris V5000; Philips Medical Systems, Eindhoven, The Netherlands) with monitoring of blood pressure and cardiac electrical activity (ECG), under local anesthesia $(10 \mathrm{ml}$ of lidocaine $2 \%$ ). In all cases, antegrade puncture of the common femoral artery was performed with the positioning of a 5F, 25-cm-long introducer (Terumo Corp., Tokyo, Japan), which was used to perform a diagnostic arteriography with non-ionic iodinated contrast media (20 ml of Iomeron 350; Bracco Imaging Italy, Milan, Italy). After systemic heparinization (50 IU/kg; 3,000-5,000 IU), the navigation of the vessels to be treated was conducted via the road map technique and with an 0.018-in. guide wire (V-18 Control Wire; Boston Scientific, Natick, MA, USA) or an 0.014-in. wire (Journey or Thruway; Boston Scientific). In cases of failure of endoluminal recanalization, a subintimal approach was used [20].

We proceeded to the positioning of small-profile balloons with size (caliber and length) chosen according to the diameter of the artery and to the length of the lesion to be treated. The balloon was inflated to a nominal pressure (10-15 atm) for 3-4 min. Repeated inflations were performed until the restoration of an adequate vessel diameter (residual stenosis $<30 \%$ of the native vessel). The PTA catheters used were Symmetry Stiff Shaft $1.5 \times 100 \mathrm{~mm}$, Sterling $2 \times 150 \mathrm{~mm}$ (Boston Scientific), Coyote $2.5 \times 150$ and $2.5 \times 220 \mathrm{~mm}$ (Boston Scientific), and, in cases of heavily calcified lesions, $2.50 \mathrm{~mm} \times 1.5 \mathrm{~cm}$ Cutting Balloon (Boston Scientific).

In all cases, as a first approach, a DR was attempted so as to recanalize the direct tributary artery feeding the skin ulcer territory (Fig. 1). In case of failure of DR due to chronic occlusion or suboptimal PTA, we proceeded to IR, which sought to improve the flow in the ulcer territory by collateral vessels (Fig. 2).

At the end of the procedure, hemostasis was achieved in all cases by means of manual compression. In the absence of 

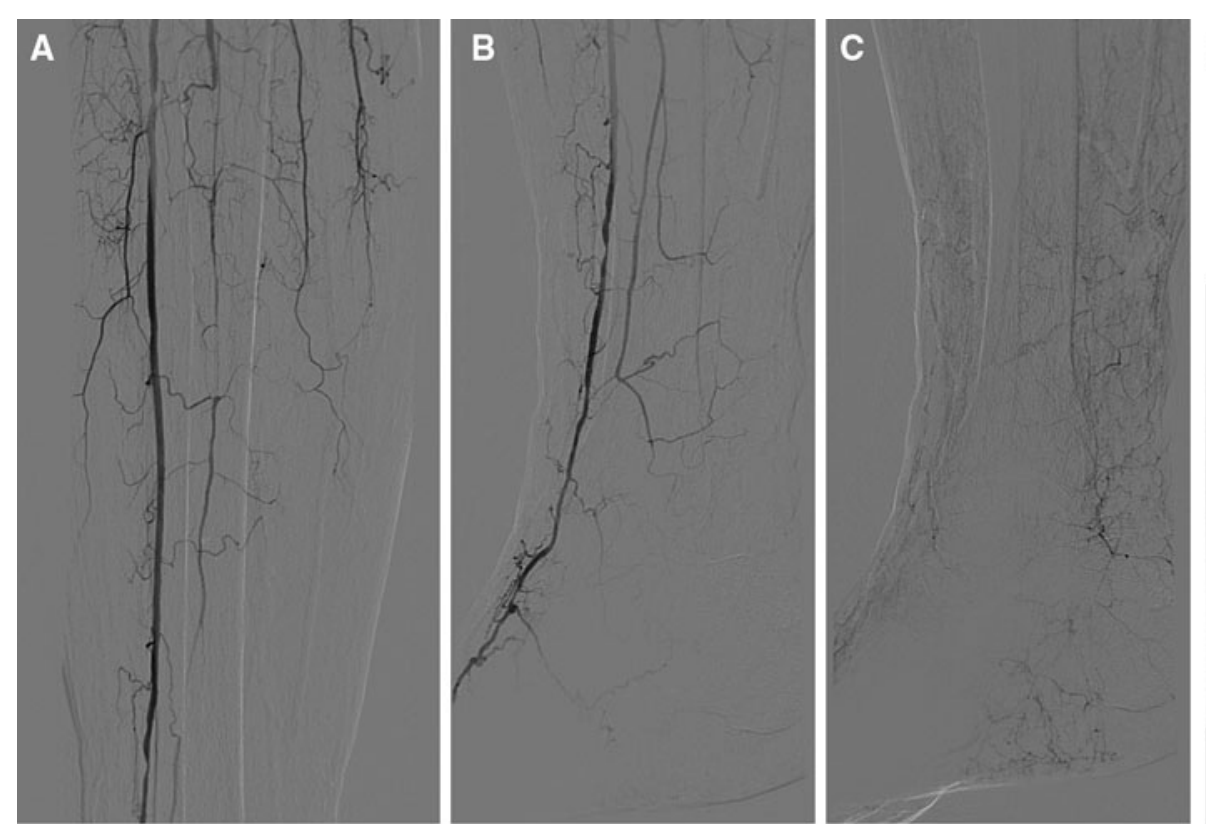

\section{D}
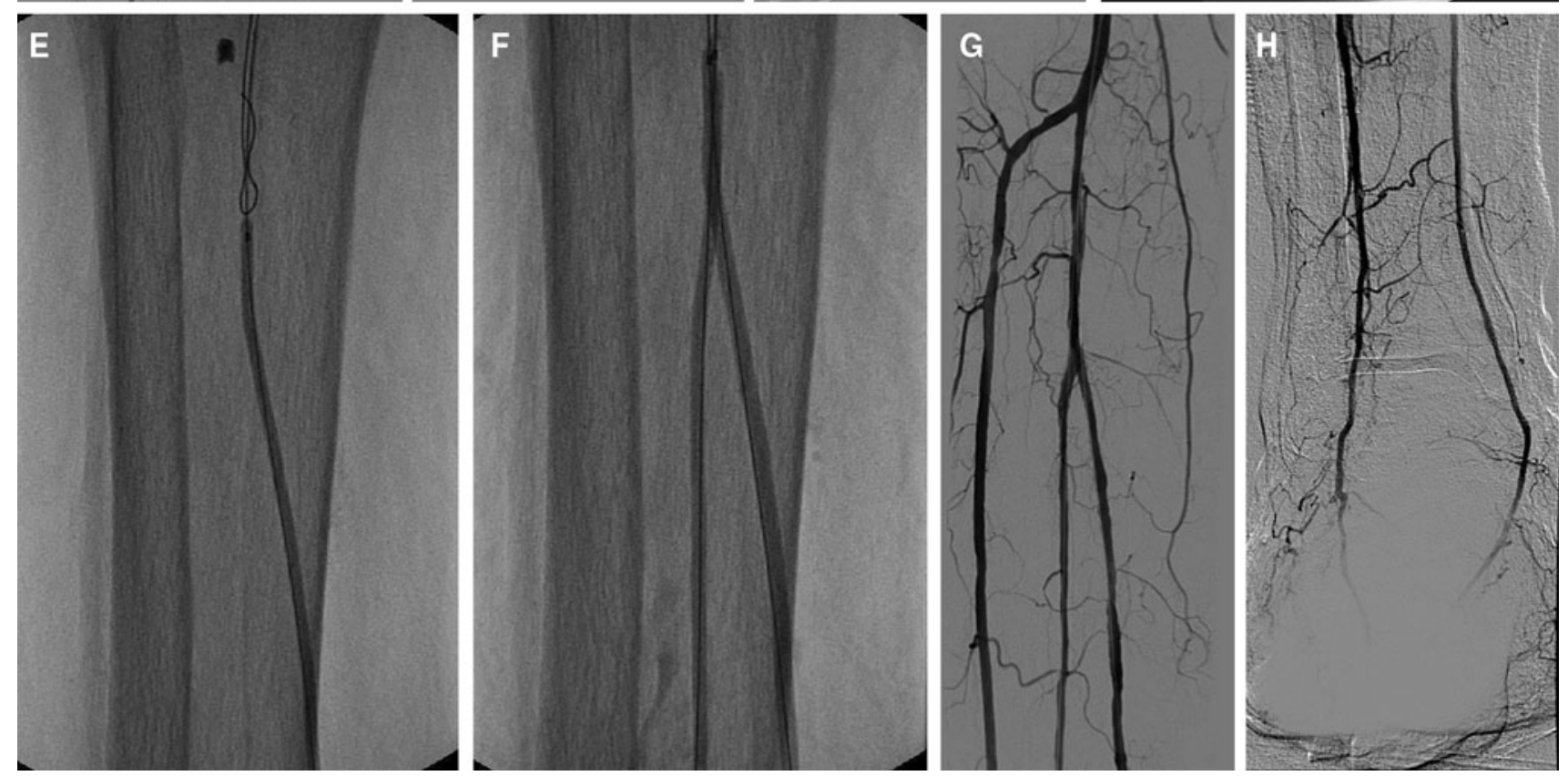

Fig. 1 Complex DR treatment of a patient with ulcers at the plant and the dorsum of the foot. Angiography reveals multiple stenosis of the anterior tibial artery and the occlusion of the posterior tibial and peroneal artery (A). Poor representation of foot vessels, with the occlusion of plantar and dorsalis pedis arteries $(\mathbf{B}, \mathbf{C})$. Through an

0.018-in. guide wire, the lumen of the leg vessels was regained, and then multiple PTA (D, E), also in kissing technique at the tibioperoneal trunk $(\mathbf{F})$, were performed. The final angiographic control documented the regained patency of the three leg vessels with the healing of the ulcer $(\mathbf{G}, \mathbf{H})$

complications, the postoperative hospital stay was 2 days. After surgery, dual antiplatelet therapy was maintained (aspirin $100 \mathrm{mg} /$ day and clopidogrel $75 \mathrm{mg} /$ day) for 6 weeks, then aspirin alone indefinitely.

The patients underwent follow-up at 1,6 , and 12 months, then every 6 months by clinical examination, measurement of $\mathrm{TcPO}_{2}$, and ultrasound color Doppler examination.

All patients were subjected to pre- and post-operative evaluation by Doppler ultrasound to identify the presence of significant stenosis and possible restenosis of the BTK area; this ensured a thorough and effective investigation in all cases.

The parameters evaluated were technical success, intended as the postoperative recovery of the calibre of the treated vessel in the absence of significant residual stenosis $(<30 \%)$, 

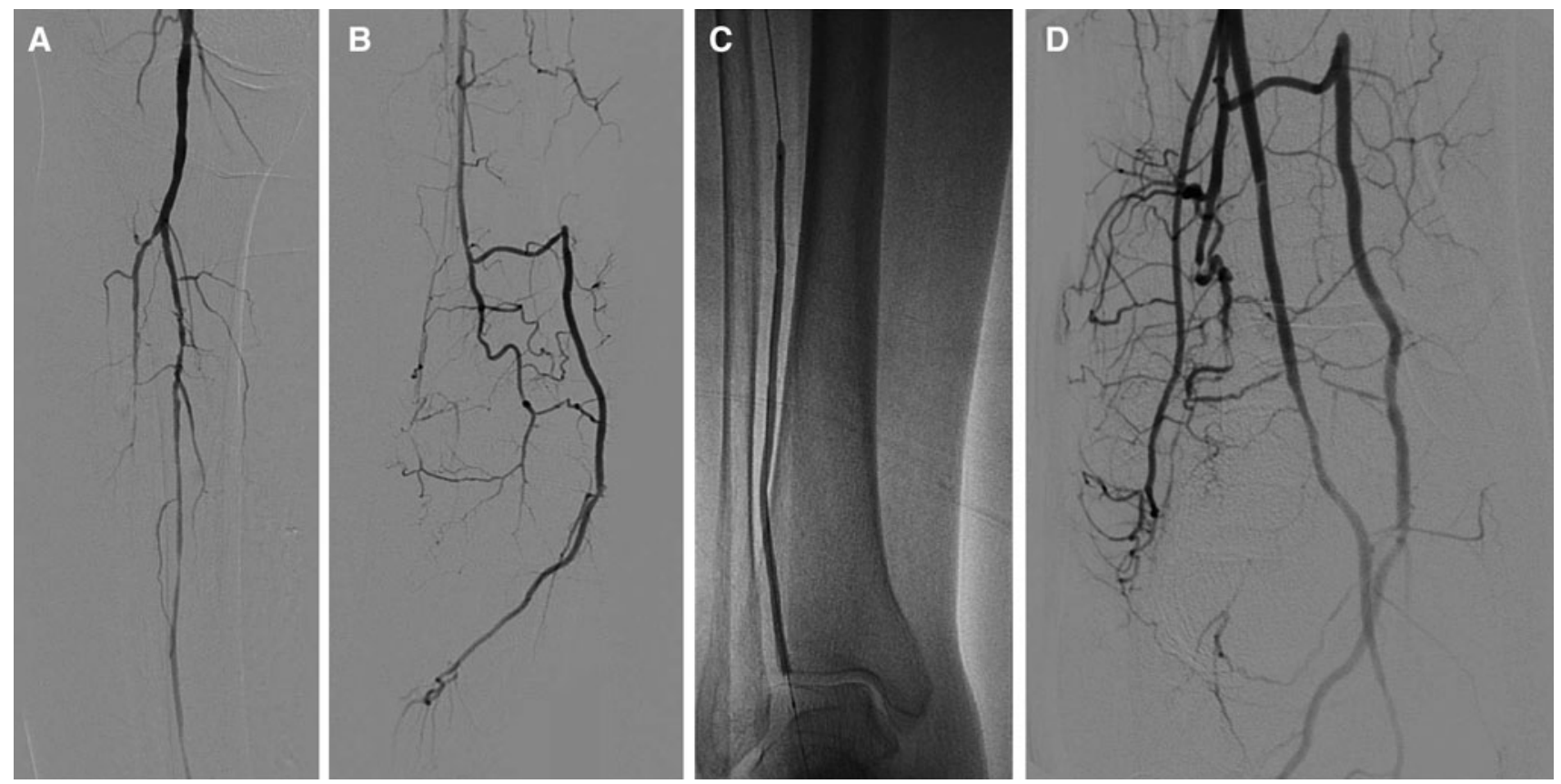

Fig. 2 IR treatment of a dorsal pedis ulcer anterior tibial artery angiosome (atn). The angiography documented occlusion of the posterior and anterior tibial arteries with patency of the peroneal

in both cases of DR and IR; incidences of partial healing (reduction in width and depth of the ulcer) and complete healing (absence of ulcerated tissue) of the ulcer; persistence of hemodynamically significant restenosis; and incidence of major and minor amputation. The rate of limb salvage, defined as being able to use the foot despite minor amputation (below the ankle) was analyzed, while only major amputation was excluded from the definition of limb salvage.

Baseline values of $\mathrm{TcPO}_{2}$ were statistically compared with those recorded at 1, 6, and 12 months by means of Student's $t$ test, considering statistically significant a $p$ value of $<0.05$.

A comparison between DR and IR groups was then made. We used Student's $t$ test to compare the values of $\mathrm{TcPO}_{2}$ observed in the two groups at 1,6 , and 12 months. We used the $\chi^{2}$ test to compare the clinical outcome between the two groups in terms of treatment success or failure, intended as major amputation $(\alpha=0.05)$. There was a similar percentage distribution of stenotic lesions and obstructive between the two groups: in the DR group, 167 patients had 246 lesions, 139 stenosis (56.5\%), and 107 occlusions (43.4\%), and in the IR group, 34 patients had 52 lesions, 29 stenosis $(55.7 \%)$, and 23 occlusions (44.2\%).

\section{Results}

From January 2005 to December 2011, at our department, 201 patients with diabetes (136 men, 65 women, mean age artery atn (A), which recanalized distally to the posterior tibial artery atn (B). PTA was performed at the level of the peroneal artery atn $(\mathbf{C})$,

Table 1 Characteristics of treated patients

\begin{tabular}{ll}
\hline Characteristics & Value \\
\hline Age (years) & $75.5 \pm 9.5$ \\
Sex (M/F) & $136 / 65$ \\
Insulin therapy & $113(56.2 \%)$ \\
Time from diagnosis of DM (years) & $12.5 \pm 5.2$ \\
Hb1Ac (\%) & $7.9 \pm 1.6$ \\
Dialysis & $15(7.4 \%)$ \\
Hypertension & $124(61.7 \%)$ \\
CAD & $65(32.3 \%)$ \\
Obesity & $46(22.8 \%)$ \\
\hline
\end{tabular}

Data are presented as $n, n(\%)$, or mean \pm standard deviation

$D M$ diabetes mellitus, $H b 1 A c$ hemoglobin A1c, CAD coronary artery disease

75.5 years, standard deviation 9.5 years) with CLI underwent PTA of the BTK vessels. Table 1 lists the patient characteristics.

A total of 298 steno-obstructive lesions were treated; 123 involved the anterior tibial artery, 103 the posterior tibial artery, and 72 the peroneal artery. Table 2 lists the lesion characteristics.

Technical success was achieved in 190 interventions $(94.5 \%)$. In 11 cases $(5.5 \%)$, the procedure was not effective. In nine cases, this was due to the presence of heavily calcified chronic occlusions that could not be with increase in vascularization in the region of the ulcer atn (D) 
Table 2 Characteristics of treated lesions

$S D$ standard deviation, $A T A$ anterior tibial artery, $P T A$ posterior tibial artery, $P A$ peroneal artery

Table 3 Results obtained at 1 , 6 , and 12 months

PTA percutaneous transluminal angioplasty, $\mathrm{TcPO}_{2}$ percutaneous oximetry $* p<0.05$

\begin{tabular}{lllllll}
\hline Artery & $n(\%)$ & \multicolumn{2}{l}{ Stenosis } & & \multicolumn{2}{l}{ Occlusions } \\
\cline { 3 - 4 } & $n$ & & Length $(\mathrm{mm})$, mean $\pm \mathrm{SD}$ & & $n$ & Length $(\mathrm{mm})$, mean $\pm \mathrm{SD}$ \\
\hline ATA & $123(41.2)$ & 65 & $106 \pm 98$ & & 58 & $202 \pm 86$ \\
PTA & $103(34.6)$ & 52 & $118 \pm 102$ & & 51 & $188 \pm 104$ \\
PA & $72(24.2)$ & 47 & $102 \pm 91$ & & 25 & $145 \pm 82$
\end{tabular}

\begin{tabular}{lllll}
\hline Results & 1 month & 6 months & 12 months & 36 months \\
\hline Major amputation & $6(2.9 \%)$ & $8(4 \%)$ & $4(2.2 \%)$ & $1(1.6 \%)$ \\
Minor amputation & $38(18.8 \%)$ & $18(9.2 \%)$ & $21(11.6 \%)$ & $4(6.6 \%)$ \\
Ulcer persistence & $5(2.4 \%)$ & & & \\
Complete healing & $41(20.4 \%)$ & $89(46 \%)$ & $99(53.4 \%)$ & $32(50.3 \%)$ \\
Partial healing & $108(54 \%)$ & $35(17.8 \%)$ & & \\
PTA retreatment & $3(1.8 \%)$ & $9(4.6 \%)$ & $4(2.2 \%)$ & $3(5 \%)$ \\
Limb salvage & & $38(18.3 \%)$ & $56(30 \%)$ & $20(33.3 \%)$ \\
Mean TcPO & $40.3 *$ & $41.3 *$ & $41.4 *$ & $46.7 *$ \\
\hline
\end{tabular}

Table 4 Results obtained at 1, 6, and 12 months in the DR group

\begin{tabular}{llll}
\hline Results & 1 month & 6 months & 12 months \\
\hline Major amputation & $6(3.6 \%)$ & $8(5 \%)$ & $2(2 \%)$ \\
Minor amputation & $31(18.5 \%)$ & $11(6.8 \%)$ & $14(10.1 \%)$ \\
Ulcer persistence & $4(2.4 \%)$ & & \\
Complete healing & $36(21.5 \%)$ & $76(47.2 \%)$ & $87(57.4 \%)$ \\
Partial healing & $87(52 \%)$ & $30(18.6 \%)$ & \\
PTA retreatment & $3(1.8 \%)$ & $9(4.6 \%)$ & $4(2.2 \%)$ \\
Limb salvage & & $29(18 \%)$ & $41(28.3 \%)$ \\
Mean TcPO & $40.8^{*}$ & $41.6 *$ & $42 *$ \\
\hline
\end{tabular}

$P T A$ percutaneous transluminal angioplasty, $\mathrm{TCPO}_{2}$ percutaneous oximetry

$* p<0.05$

overcome with guide wires, and in two cases, it was due to the onset of an important vagal crisis, treated with atropine, that required immediate suspension of the procedure.

The average value of preoperative $\mathrm{TcPO}_{2}$ was $25.1 \mathrm{mmHg}$.

Follow-up was performed in all patients at 1, 6, and 12 months. Results are listed in Table 3.

By means of Student's $t$ test, the baseline values of $\mathrm{TcPO}_{2}$ were compared to those recorded at 1,6 , and 12 months, and a statistically significant increase was found $(p<0.005$, Table 3).

At 1 year, we observed 18 major amputations (8.9\%), 77 minor amputations (38.3\%), 99 complete healings $(49.2 \%)$, and 7 deaths (3.5\%), all for diseases not related to treatment (4 for myocardial infarctions, 2 strokes, 1 sepsis).

At the ultrasound Doppler evaluation, we found 80 restenosis $(39.8 \%)$. Sixty-six were symptomatic, with
Table 5 Results obtained at 1, 6, and 12 months in the IR group

\begin{tabular}{llll}
\hline Results & 1 month & 6 months & 12 months \\
\hline Major amputation & $0(0 \%)$ & $0(0 \%)$ & $3(8.8 \%)$ \\
Minor amputation & $7(20.5 \%)$ & $7(20.5 \%)$ & $7(20.5 \%)$ \\
Ulcer persistence & $1(3 \%)$ & $0(0 \%)$ & \\
Complete healing & $5(14.7 \%)$ & $13(38.2 \%)$ & $11(32.3 \%)$ \\
Partial healing & $21(61.7 \%)$ & $5(14.7 \%)$ & \\
PTA retreatment & $0(0 \%)$ & $2(5.9 \%)$ & $4(2.2 \%)$ \\
Limb salvage & & $7(20.5 \%)$ & $14(41.2 \%)$ \\
Mean TcPO & $40.6^{*}$ & $39.9 *$ & $38.2 *$ \\
\hline
\end{tabular}

PTA percutaneous transluminal angioplasty, $\mathrm{TcPO}_{2}$ percutaneous oximetry

$* p<0.05$

recurrent and worsening ulcer, and the patients underwent further treatment. Fourteen were asymptomatic, with no recurrence or worsening ulcer, and thus were not treated. Treatment was provided in 16 cases with PTA ( $8 \%$ of treatments), in 12 cases with major amputation, and in 38 cases with minor amputation.

Sixty patients had 36 months' follow-up, with the following results: 4 minor amputations $(6.6 \%), 1$ major amputation (1.6\%), 32 complete healing (53.3\%), and 3 retreatments by PTA (5\%). Twenty patients, who had previously undergone a minor amputation, were free from diabetic foot complication (limb salvage); the average $\mathrm{TcPO}_{2}$ was $46.7 \mathrm{mmHg}$, which was significantly increased from baseline data $(p<0.05)$.

Overall, at a median \pm standard deviation follow-up of $17.5 \pm 12$ months, we observed an incidence of mortality 
of $3.5 \%$ (7 of 201), major amputations of $9.4 \%$ (19 of 201), minor amputations of $40.3 \%$ (81 of 201), and complete healing of $46.7 \%$ (94 of 201), for an incidence of limb salvage of $87 \%$ (175 of 201). The rate of restenosis was $39.8 \%$ (80 of 201) with an incidence of retreatment with PTA of $9.4 \%$ (19 of 201).

In 34 patients ( $16.9 \%)$, the treatment was performed via the IR technique. Table 4 lists the results observed in the DR group and Table 5 the IR group. In both groups, there was a statistically significant increase of $\mathrm{TcPO}_{2}$ values measured at 1,6 , and 12 months compared to baseline values $(p<0.05)$; the comparison of the values of $\mathrm{TcPO}_{2}$ measured at 1,6 , and 12 months between the two groups revealed no statistically significant difference $(p<0.05)$.

In the DR group, we observed a total of 16 of 167 major amputations $(9.6 \%)$, with a limb salvage rate of $90.4 \%$, while in the IR group we observed three major amputations $(8.8 \%)$, with a limb salvage rate of $91.2 \%$. The comparison of the effectiveness of the treatment in the two groups (failure: major amputation, success: limb salvage), performed by the $\chi^{2}$ test, revealed no statistically significant differences $\left(\chi^{2}\right.$ value, 1 month: 1.26; 6 months: 3.06 ; 12 months: 0.02 , for $\alpha=0.05$ ).

\section{Discussion}

Diabetic foot treatment is a major challenge for specialists in the field. Bypass surgery, which is still the standard procedure [21], requires the presence of a good venous conduit and at least one patent artery in the region of leg, and it is subjected to a non-negligible rate of perioperative mortality $(0.9 \%)$, serious cardiac complications (myocardial infarction or acute heart failure rate of about $3 \%$ ), and retreatment (thrombosis, bleeding, or infection rate of about $6.6 \%$ ) [22].

PTA has established itself as a first-line treatment for CLI in patients with diabetic foot, with similar results to surgery in terms of limb salvage and patency [8-10]. The main studies in the literature [13, 16, 23-30] reported, for endovascular treatment, a technical success rate of about $90 \%$, a negligible mortality rate, and a limb salvage rate at 3-5 years of 72-98\%.

The only randomized trial comparing surgical and endovascular treatment, the BASIL trial [31], documented a similar result between the two techniques in terms of limb salvage and overall survival at 1 year, but among patients who survived to 2 years, the survival rate and limb salvage was greater in the surgical group. In a meta-analysis comparing the results of the surgical and endovascular approach of BTK area, Romiti et al. [32] reported a rate of limb salvage at 3 years that was comparable for the two techniques (PTA $82.4 \pm 3.4$, surgery $82.3 \pm 3.0$ ). Several other studies [23-30] evaluated the effectiveness of PTA in diabetic foot patients, but these studies are limited by their main conditions, including a heterogeneous population with BTK and/or ATK disease. Moreover, the effectiveness of BTK-area PTA is still a matter of debate; the small size of the treated vessels appears to be associated with an increased rate of restenosis, and in patients with chronic ATK and BTK knee disease, it is unclear whether the clinical success is linked to the PTA of either the ATK or BTK area alone [33].

For this reason, in our retrospective study, we selected a homogeneous population of patients with BTK disease to assess the effectiveness of PTA in that area alone, which is the elective site of steno-obstructive disease in diabetic patients [18]. In the literature, we found only one similar study, by Ferraresi et al. [30], with 101 BTK-alone diabetic patients with CLI treated with PTA that demonstrates, at a mean follow-up of $2.9 \pm 1.4$ years, a limb salvage rate of $93 \%$, a major amputation rate of $7 \%$, and a minor amputation rate of $64 \%$.

Our results are in line with those of Ferraresi et al. [30]. At a mean follow-up of $17.5 \pm 12$ months, we observed a limb salvage rate of $87 \%$, a major amputation rate of $9.4 \%$, and a mortality rate of $3.5 \%$. The rate of restenosis was $39.8 \%$ (80 of 201), with a PTA retreatment incidence of $9.4 \%$ (19 of 201). We observed a statistically significant increase of $\mathrm{TcPO}_{2}$ values at 1,6 , and 12 months, indicating the effectiveness of the endovascular treatment in the short and medium term.

In our experience, endovascular treatment of the BTK area therefore gives satisfactory results, and in agreement with studies reported in the literature [30], we believe that the PTA of these vessels decisively contributes to the treatment of CLI in diabetic patients.

The results we observed are in agreement with the recent guidelines of the European Society for Vascular Surgery on the treatment of diabetic foot [34], which notes, "Endovascular therapy for infrapopliteal arterial disease is gaining acceptance as a first-line revascularization method to improve ulcer healing and limb salvage." We also agree with the recommendation of these guidelines: "The choice between different methods of revascularization-open, endovascular or hybrid-depends on comorbidity, severity and extension of the arterial lesions as well as the expertise of the center (Level 2c; Grade B)" [34].

In recent years, on the basis of anatomical studies by Taylor and Pan [35] and Attinger et al. [36], the angiosome model was developed. Angiosomes are the areas in which the human body is divided according to arterial and venous distributions. The foot is divided into five angiosomes: the medial calcaneal; the medial plantar; the lateral plantar, which arises from the posterior tibial artery; the dorsal foot angiosome, which arises from the anterior tibial artery; 
and finally the lateral calcaneal angiosome, which derives from the peroneal artery $[35,36]$. The angiosome model was then introduced into clinical practice to test its effectiveness in terms of limb salvage. DR is considered the treatment of an artery that is a direct tributary of the involved angiosome, whereas IR is intended as the treatment of an artery that is not a direct tributary of the involved angiosome [37]. Studies seem to favor the effectiveness of DR according to the angiosome model [37-40].

In a retrospective study of 48 patients treated surgically, Neville et al. [37] found a rate of limb salvage of $91 \%$ in the DR group compared to $62 \%$ in the IR group. In 203 consecutive patients with CLI treated endovascularly, Iida et al. [38] reported $86 \%$ of limb salvage rate in the DR group compared to $69 \%$ in the IR group. Similar results were reported by Varela et al. [39] and by Alexandrescu et al. [40], documenting how the treatment of diabetic patients with CLI throughout DR provide better results in terms of limb salvage and ulcer healing than IR.

At our institute, the first treatment option is DR, a strategy that is in line with data from the literature [37-40]. Only in cases of technical impossibility of DR do we turn to our second choice, the indirect approach. In our experience, treatment with IR, which was reserved for only 34 patients, was effective; we observed an incidence of major amputation of $8.8 \%$ (vs. $9.6 \%$ in the group DR) and limb salvage rate of $91.2 \%$ (90.4\% vs. the DR group), with a statistically significant increase of $\mathrm{TcPO}_{2}$ values at 1,6 , and 12 months compared to baseline values. The statistical comparison between the DR and the IR group performed by the $\chi^{2}$ test did not indicate significant differences in terms of therapeutic success (limb salvage rate vs. major amputation) at 1, 6, and 12 months.

These findings, although limited by the small number of patients in the IR group, are in agreement with those reported by Dosluoglu et al. [12] and document how the indirect treatment of the affected angiosome is an effective option in cases of a technical inability to use a DR.

The limitations of our study include its retrospective nature and the small number of patients in the IR group compared with the DR group. We believe, however, that is important to report our experience in the treatment of diabetic foot in a selected population of patients with BTK disease and to evaluate the effectiveness of different treatment options according to the angiosome model, because it remains a topic of great debate and there are no definitive answers.

In conclusion, our study demonstrated that PTA in diabetic patients with BTK disease is a safe and effective option, with good results in terms of limb salvage and ulcer healing in the medium term. In our opinion, the DR technique, according to the literature [37-40], should be the first therapeutic choice; however, if DR treatment is not feasible, then the IR technique is a valid and similarly effective procedure.

Conflict of interest The authors declare that they have no conflict of interest.

\section{References}

1. Kalish J, Hamdan A (2010) Management of diabetic foot problems. J Vasc Surg 51:476-486

2. Diabetes Atlas. http://www.diabetesatlas.org. Accessed August 2012

3. International Working Group on the Diabetic Foot (2011) International Consensus on the Diabetic Foot and Practical Guidelines on the Management and the Prevention of the Diabetic Foot. International Working Group on the Diabetic Foot, Amsterdam

4. Boulton AJ, Vileikyte L, Ragnarson-Tennvall G et al (2005) The global burden of diabetic foot disease. Lancet 366(9498): 1719-1724

5. Apelqvist J, Larsson $\mathbf{J}$ (2000) What is the most effective way to reduce incidence of amputation in the diabetic foot? Diabetes Metab Res Rev 16(suppl 1):S75-S83

6. Apelqvist J, Larsson J, Agardh CD (1993) Long-term prognosis for patients with diabetic ulcers. J Intern Med 233:485-491

7. Johannesson A, Larsson GU, Ramstrand N et al (2009) Incidence of lower-limb amputation in the diabetic and non-diabetic general population: a 10-year population-based cohort study of initial unilateral and contralateral amputations and reamputations. Diabetes Care 32:275-280

8. Soderstrom MI, Arvela EM, Korhonen M et al (2010) Infrapopliteal percutaneous transluminal angioplasty versus bypass surgery as first-line strategies in critical leg ischemia: a propensity score analysis. Ann Surg 252:765-773

9. Faglia E, Clerici G, Clerissi J et al (2007) When is a technically successful peripheral angioplasty effective in preventing abovethe-ankle amputation in diabetic patients with critical limb ischaemia? Diabet Med 24:823-829

10. Sigala F, Menenakos Ch, Sigalas P et al (2005) Transluminal angioplasty of isolated crural arterial lesions in diabetics with critical limb ischemia. Vasa 34:186-191

11. Met R, Van Lienden KP, Koelemay MJ et al (2008) Subintimal angioplasty for peripheral arterial occlusive disease: a systematic review. Cardiovasc Interv Radiol 31:687-697

12. Dosluoglu HH, Cherr GS, Lall P et al (2008) Peroneal artery-only runoff following endovascular revascularizations is effective for limb salvage in patients with tissue loss. J Vasc Surg 48:137-143

13. Faglia E, Dalla Paola L, Clerici G et al (2005) Peripheral angioplasty as the first-choice revascularization procedure in diabetic patients with critical limb ischemia: prospective study of 993 consecutive patients hospitalized and followed between 1999 and 2003. Eur J Vasc Endovasc Surg 29:620-627

14. Graziani L, Piaggesi A (2010) Indications and clinical outcomes for below knee endovascular therapy: review article. Catheter Cardiovasc Interv 75:433-443

15. Bosiers M, Hart JP, Deloose K et al (2006) Endovascular therapy as the primary approach for limb salvage in patients with critical limb ischemia: experience with 443 infrapopliteal procedures. Vascular 14:63-69

16. Brillu C, Picquet J, Villapadierna F et al (2001) Percutaneous transluminal angioplasty for management of critical ischemia in arteries below the knee. Ann Vasc Surg 15:175-181

17. Schillinger M, Exner M, Mlekusch W et al (2003) Endovascular revascularization below the knee: 6-month results and predictive value of c-reactive protein level. Radiology 227:419-425 
18. Diehm N, Shan A, Silvestro A et al (2006) Association of cardiovascular risk factors with pattern of lower limb atherosclerosis in 2659 patients undergoing angioplasty. Eur J Vasc Endovasc Surg 31:59-63

19. Alexandrescu V, Hubermont G (2011) Primary infragenicular angioplasty for diabetic neuroischemic foot ulcers following the angiosome distribution: a new paradigm for the vascular interventionist? Diabetes Metab Syndr Obes 4:327-336

20. Ingle H, Nasim A, Bolia A et al (2002) Subintimal angioplasty of isolated infragenicular vessels in lower limb ischemia: long term results. J Endovasc Ther 9:411-416

21. Aulivola B, Pomposelli FB (2004) Dorsalis pedis, tarsal and plantar artery bypass. J Cardiovasc Surg 45:203-212

22. Pomposelli FB, Kansal N, Hamdan AD et al (2003) A decade of experience with dorsalis pedis artery bypass: analysis of outcome in more than 1000 cases. J Vasc Surg 37:307-315

23. Dorros G, Jaff MR, Dorros AM et al (2001) Tibioperoneal (outflow lesion) angioplasty can be used as a primary treatment in 235 patients with critical limb ischemia: five-year follow-up. Circulation 104:2057-2062

24. Lofberg AM, Lorelius LE, Karacagil S et al (1996) The use of below-knee percutaneous transluminal angioplasty in arterial occlusive disease casing chronic critical limb ischemia. Cardiovasc Interv Radiol 19:317-322

25. Soder HK, Manninen HI, Jaakkola P et al (2000) Prospective trial of infrapopliteal artery balloon angioplasty for critical limb ischemia: angiographic and clinical results. J Vasc Interv Radiol 11:1021-1031

26. Rand T, Basile A, Cejna M et al (2006) PTA versus carbofilmcoated stents in infrapopliteal arteries: pilot study. Cardiovasc Interv Radiol 29:29-38

27. Staffa R, Leypold J, Vojtísek B (2003) Pedal bypass versus PTA (percutaneous transluminal angioplasty) of the crural arteries. Rozhl Chir 82(10):516-521

28. Matsagas MI, Rivera MA, Tran T et al (2003) Clinical outcome following infrainguinal percutaneous transluminal angioplasy for critical limb ischemia. Cardiovasc Interv Radiol 26:251-255

29. Balmer H, Mahler F, Do D, Triller J et al (2002) Balloon angioplasty in chronic critical limb ischemia: factors affecting clinical and angiographic outcome. J Endovasc Ther 9:403-410
30. Ferraresi R, Centola M, Ferlini M et al (2008) Long-term outcomes after angioplasty of isolated, below-the-knee arteries in diabetic patients with critical limb ischaemia. Eur J Vasc Endovasc Surg 37:336-342

31. Bradbury AW (2010) Bypass Versus Angioplasty in Severe Ischaemia of the Leg (BASIL) trial in perspective. J Vasc Surg 51(suppl): $1 \mathrm{~S}-4 \mathrm{~S}$

32. Romiti M, Albers M, Brochado-Neto FC et al (2008) Metaanalysis of infrapopliteal angioplasty for chronic critical limb ischemia. J Vasc Surg 47:975-981

33. Conrad MF, Cambria RP, Stone DH et al (2006) Intermediate results of percutaneous endovascular therapy of femoropopliteal occlusive disease: a contemporary series. J Vasc Surg 44: 762-769

34. Lepäntalo M, Apelqvist J, Setacci C et al (2011) Chapter V: diabetic foot. Eur J Vasc Endovasc Surg 42(suppl 2):S60-S74

35. Taylor GI, Pan WR (1997) Angiosomes of the leg: anatomic study and clinical implications. Plast Reconstr Surg 4:183-198

36. Attinger CE, Evans KK, Bulan E et al (2006) Angiosomes of the foot and ankle and clinical implications for limb salvage: reconstruction, incisions and revascularization. Plast Reconstr Surg 117(7 suppl):261S-293S

37. Neville RF, Attinger CE, Bulan EJ et al (2009) Revascularization of a specific angiosome for limb salvage: does the target artery matter? Ann Vasc Surg 23:367-373

38. Iida O, Nanto $S$, Uematsu $M$ et al (2010) Importance of the angiosome concept for endovascular therapy in patients with critical limb ischemia. Catheter Cardiovasc Interv 75:830-836

39. Varela C, Aci NF, Haro JD et al (2010) The role of foot collateral vessels on ulcer healing and limb salvage after successful endovascular and surgical distal procedures according to an angiosome model. Vasc Endovasc Surg 44:654-660

40. Alexandrescu V, Hubermont G, Philips Y et al (2008) Selective angioplasty following an angiosome model of reperfusion in the treatment of Wagner 1-4 diabetic foot lesions: practice in a multidisciplinary diabetic limb service. J Endovasc Ther 15: 580-593 